University of Wollongong

Research Online

Faculty of Engineering and Information

Faculty of Engineering and Information

Sciences - Papers: Part A

Sciences

$1-1-2015$

\title{
A study of the behaviour of fresh and coal fouled ballast reinforced by geogrid using the discrete element method
}

Ngoc Trung Ngo

University of Wollongong, trung@uow.edu.au

Buddhima Indraratna

University of Wollongong, indra@uow.edu.au

Cholachat Rujikiatkamjorn

University of Wollongong, cholacha@uow.edu.au

Follow this and additional works at: https://ro.uow.edu.au/eispapers

Part of the Engineering Commons, and the Science and Technology Studies Commons

Research Online is the open access institutional repository for the University of Wollongong. For further information contact the UOW Library: research-pubs@uow.edu.au 


\title{
A study of the behaviour of fresh and coal fouled ballast reinforced by geogrid using the discrete element method
}

\begin{abstract}
Geogrids are widely used in ballasted rail tracks for reinforcement and stabilisation. During train operation, ballast becomes contaminated or fouled due to infiltration of fines from the surface, mud pumping from the subgrade, and degradation, which decreases the performance of the geogrids. This paper presents the results of a laboratory and numerical simulation to study the effect that coal fines have on the interface between ballast and geogrid. The stress-strain behaviour of fresh and fouled ballast reinforced by geogrid was investigated via a series of large scale direct shear tests in the laboratory and numerical simulations using the Discrete Element Method (DEM). The geogrid was modelled by bonding a large number of small spheres together to form the desired geometry and apertures. Irregular particle shapes were simulated in DEM by connecting many spheres together in appropriate sizes and positions. Fouled ballast was modelled by adding a predetermined amount of miniature spheres into the voids of the fresh ballast. The DEM results were then compared qualitatively with the laboratory data, and the effects of fines on the resulting shear stress-strain of ballast and the contact forces developed in the geogrids are discussed.
\end{abstract}

\section{Keywords}

discrete, geogrid, ballast, element, fouled, study, reinforced, coal, method, fresh, behaviour

\section{Disciplines}

Engineering | Science and Technology Studies

\section{Publication Details}

Ngo, N. T., Indraratna, B. \& Rujikiatkamjorn, C. (2015). A study of the behaviour of fresh and coal fouled ballast reinforced by geogrid using the discrete element method. In K. Soga, K. Kumar, G. Biscontin \& M. Kuo (Eds.), Geomechanics from Micro to Macro (pp. 559-563). United Kingdom: Taylor \& Francis. 


\title{
A study of the behaviour of fresh and coal fouled ballast reinforced by geogrid using the discrete element method
}

\author{
Ngo, N.T., Indraratna, B., \& Rujikiatkamjorn, C. \\ Centre for Geomechanics and Railway Engineering, Faculty of Engineering and Information Sciences, ARC \\ Centre of Excellence for Geotechnical Science and Engineering, University of Wollongong, Wollongong, \\ NSW 2522, Australia
}

\begin{abstract}
Geogrids are widely used in ballasted rail tracks for reinforcement and stabilisation. During train operation, ballast becomes contaminated or fouled due to infiltration of fines from the surface, mud pumping from the subgrade, and degradation, which decreases the performance of the geogrids. This paper presents the results of a laboratory and numerical simulation to study the effect that coal fines have on the interface between ballast and geogrid. The stress-strain behaviour of fresh and fouled ballast reinforced by geogrid was investigated via a series of large scale direct shear tests in the laboratory and numerical simulations using the discrete element method (DEM). The geogrid was modelled by bonding a large number of small spheres together to form the desired geometry and apertures. Irregular particle shapes were simulated in DEM by connecting many spheres together in appropriate sizes and positions. Fouled ballast was modelled by adding a predetermined amount of miniature spheres into the voids of the fresh ballast. The DEM results were then compared qualitatively with the laboratory data, and the effects of fines on the resulting shear stressstrain of ballast and the contact forces developed in the geogrids are discussed.
\end{abstract}

\section{INTRODUCTION}

Ballast helps to transmit and distribute axle loads from the sleepers to the sub-ballast layer (Selig and Waters 1994). It usually consists of medium to coarse particles whose main functions are to: (i) transfer train loads to the lower layers at reduced and acceptable levels of stress, (ii) offer lateral resistance to the tracks, and (iii) facilitate free draining conditions. Upon repeated train loading the ballast deteriorates because the sharp corners break, external fines steadily infiltrate, and mud is pumped up from the subgrade. As a consequence the ballast becomes fouled, less angular, and hence its shear strength is decreased (Indraratna et al. 2011, 2013a). Feldman $\&$ Nissen (2002) reported that for freight corridors in Australia that are predominantly used to transport coal, coal fines account for $70 \%-95 \%$ of contaminants and ballast breakdown contributes from 5\% $30 \%$.

Geogrids have been increasingly used in ballasted rail tracks to reinforce and confine the ballast layer (Bathurst and Raymond 1987; Raymond 2002; Brown et al. 2007; Indraratna et al. 2013; Ngo et al. 2014). A geogrid installed between granular layers interacts with the surrounding aggregates to carry tensile loads induced by the cyclic train loadings. The effectiveness of geogrid mainly depends on its geometry, stiffness, cross-sectional shape of the rib, and strength at the junctions (Shukla and Yin 2006; Brown et al. 2007).

When ballast becomes fouled the interaction between it and the geogrid may change substantially, because fine particles clog in the pore matrix of the ballast assembly and reduce the mechanical interlocking between the ballast and geogrid. There have been limited attempts to study fouled ballast both in the laboratory and via numerical simulations (McDowell et al. 2006; Tutumluer et al. 2011; Ferellec \& McDowell 2012). In these studies fresh ballast was modelled with unrealistic shapes and they did not examine the influence of particle shape and accumulated fouling materials on the track performance. This paper presents the results of the experimental and numerical simulation of large-scale direct shear tests of fouled ballast reinforced by geogrid, subjected to relatively low normal stresses ranging from $27 \mathrm{kPa}$ to $75 \mathrm{kPa}$. 


\section{EXPERIMENTAL INVESTIGATION}

A series of large scale direct shear tests on $300 \times$ $300 \times 200 \mathrm{~mm}$ specimens were conducted. To eliminate the boundary effect, slightly smaller ballast with the largest particle size of $40 \mathrm{~mm}$ was used (Indraratna et al. 2011). Dry coal fines were used as fouling material and the Void Contaminant Index (VCI) introduced earlier by Indraratna et al. (2010), was used to quantify the fouling levels, as given by:

$V C I=\frac{1+e_{f}}{e_{b}} \times \frac{G_{s . b}}{G_{s . f}} \times \frac{M_{f}}{M_{b}} \times 100$

where $e_{f}=$ void ratio of fouling material, $e_{b}=$ the void ratio of fresh ballast, $G_{s . b}=$ the specific gravity of ballast, $G_{s . f}=$ the specific gravity of fouling material, $M_{f}=$ the dry mass of fouling material, $M_{b}=$ the dry mass of fresh ballast. By sub-dividing the ballast assembly into small layers, a predetermined amount of coal fines were uniformly distributed into the void space to represent field conditions at any given VCI. The particle size distributions of materials tested in this study are shown in Figure 1. The geogrid used in this study was manufactured from polypropylene and had $40 \mathrm{~mm} \times 40 \mathrm{~mm}$ apertures. The ballast was placed in the shear box and compacted to a field density of $15.3 \mathrm{kN} / \mathrm{m}^{3}$. A view of the large scale direct shear apparatus is shown in Figure $2 \mathrm{a}$ and a schematic diagram of this test set up are shown in Figure 2b. A sheet of geogrid was horizontally placed in the mid plane of the shear box and secured to the apparatus by clamping it to the bottom half of the box with anchors. A predetermined amount of coal fines was added to fresh ballast to meet the desired VCI. These coal fines then migrated and accumulated into voids between ballast aggregates under gravity and induced compaction. The normal stress was applied via a rigid plate on top of the shear box and a dead weight system attached to a lever arm. The tests were conducted at three normal stresses of 27,51 , and $75 \mathrm{kPa}$ and were sheared to a horizontal displacement of $37 \mathrm{~mm}$ (i.e. shear strain of 13.3\%) at a shearing rate of $2.5 \mathrm{~mm} / \mathrm{min}$. During this process the shear forces and vertical movement of the top plate were recorded at every $1 \mathrm{~mm}$ of horizontal displacement. The experimental results of the shear test will be compared with numerical simulation and presented in the next Section.

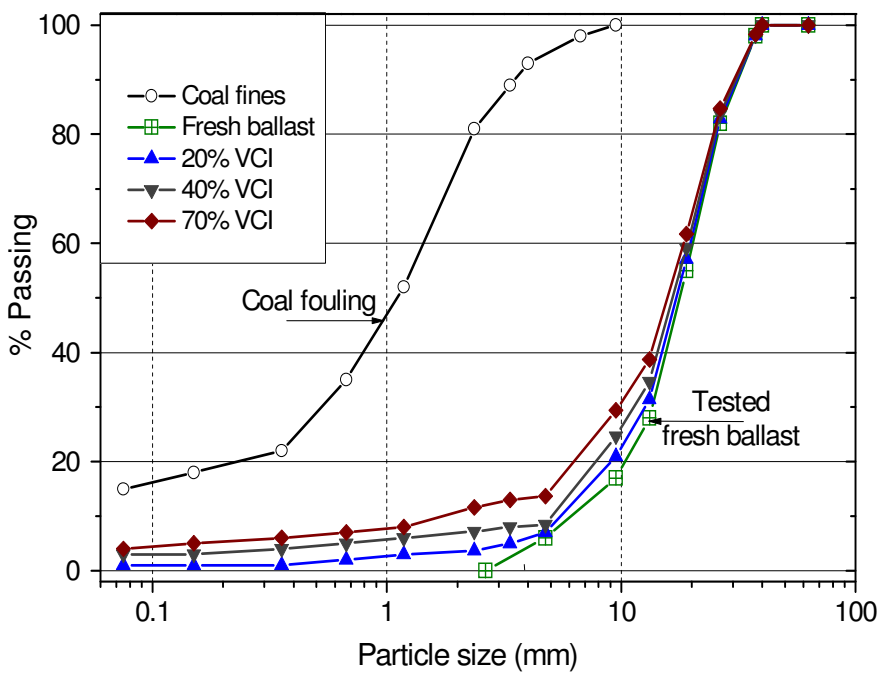

Figure 1. Particle size distributions of ballast and coal fines tested in the laboratory

\section{NUMERICAL SIMULATION OF DIRECT SHEAR TEST}

A Particle Flow Code (PFC3D) based on the Discrete Element Method (DEM) introduced by (Cundall and Strack 1979) was used to model the large scale direct shear test. The irregularly shaped grains of ballast were simulated via "clump logic", i.e., a method of creating irregular particles by connecting and overlapping a number of different sizes and coordinates (Itasca 2008). This method has been widely used by Lim and McDowell (2005); Lu and McDowell (2007); Ferellec and McDowell (2008) and Thakur et al. (2010). With this method, a choice of nine typical ballast shapes and the simulated direct shear box conditions developed earlier by the authors (Indraratna et al. 2013b) were available for the current analysis, as shown in Figure 3a.

Geogrid with $40 \mathrm{~mm} \times 40 \mathrm{~mm}$ size apertures, similar to that tested in the experiment, was simulated by connecting a number of small spheres together (i.e., balls with a $2 \mathrm{~mm}$ radius at the ribs and a $4 \mathrm{~mm}$ radius at the junctions). These balls were connected by parallel bond strengths that represented the geogrid's tensile strength. The simulated large scale direct shear tests in DEM for fresh and 40\%VCI-fouled ballast are shown in Figures 3(b) and 3(c), respectively. By calibrating with the experimental results presented by Indraratna et al. (2011), a set of micromechanical parameters adopted for DEM simulation of fresh and fouled ballast reinforced by geogrid are presented in Table 1. 


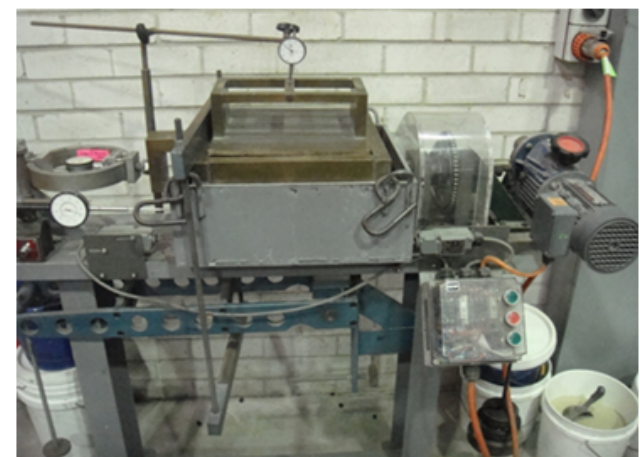

(a)

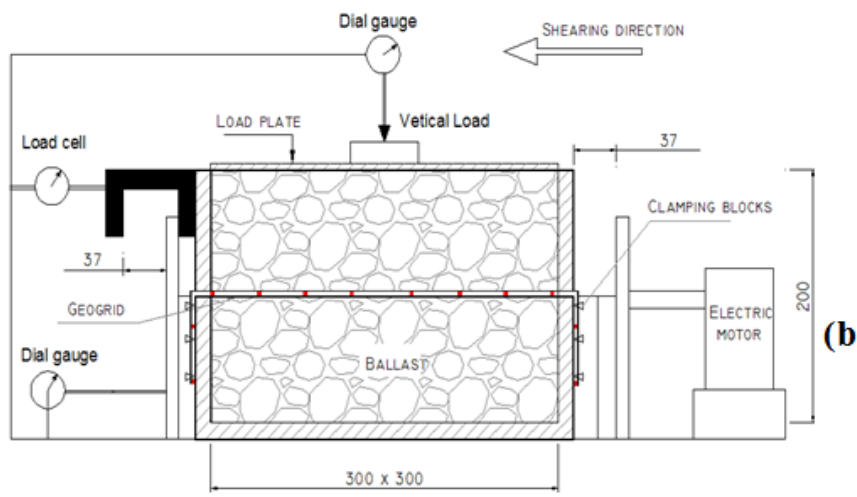

Figure 2. (a) photo of direct shear apparatus ; (b) Schematic diagram of the test set up (dimensions are in $\mathrm{mm}$ )

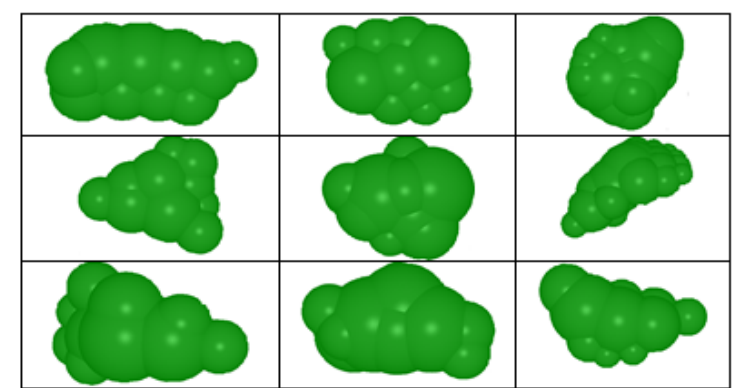

(a)

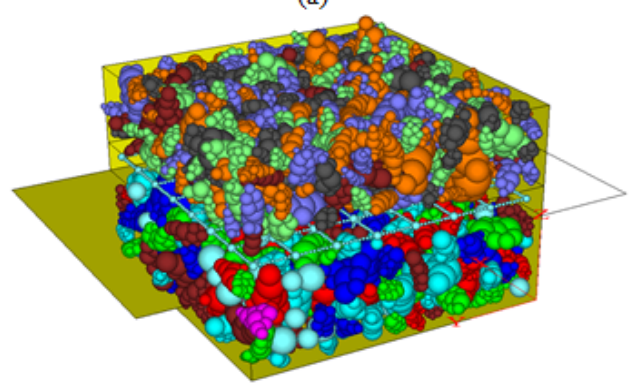

(b)

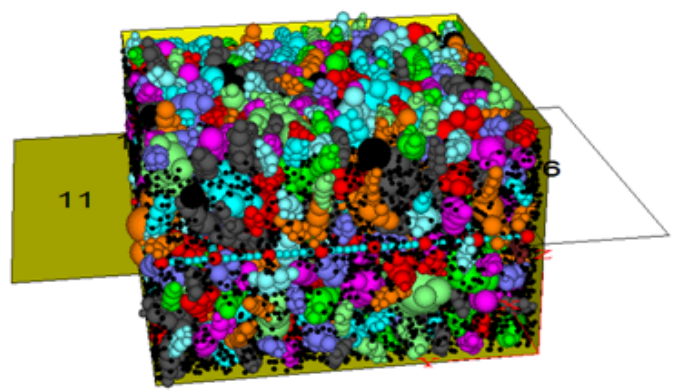

(c)

Figure 3. (a) choice of ballast particle shapes modeled in DEM; (b) DEM model for fresh ballast; (c) DEM model for $40 \%$ fouled ballast (modified after Indraratna et al. 2013b)
Table 1. Micromechanical parameters of geogrid, ballast and coal fines adopted in DEM simulation

\begin{tabular}{|l|l|l|l|}
\hline \multicolumn{1}{|c|}{ Parameter } & Geogrid & Ballast & $\begin{array}{l}\text { Coal } \\
\text { fines }\end{array}$ \\
\hline $\begin{array}{l}\text { Particle density }\left(\mathrm{kg} / \mathrm{m}^{3)}\right. \\
\text { Coefficient of friction } \\
\text { Contact normal stiffness, } \\
k_{n}(\mathrm{~N} / \mathrm{m})\end{array}$ & 800 & 2700 & 800 \\
$\begin{array}{l}\text { Contact shear stiffness, } k_{s} \\
(\mathrm{~N} / \mathrm{m})\end{array}$ & $0.88 \times 10^{7}$ & $0.52 \times 10^{8}$ & $1.27 \times 10^{4}$ \\
$\begin{array}{l}\text { Contact normal stiffness } \\
\text { of wall-particle, } \mathrm{k}_{\mathrm{n}-\mathrm{wall}}\end{array}$ & $1 \times 10^{8}$ & $1 \times 10^{8}$ & $1 \times 10^{8}$ \\
$\begin{array}{l}\mathrm{N} / \mathrm{m}) \\
\text { Shear stiffness of wall of } \\
\text { wall-particle, } \mathrm{k}_{\mathrm{s} \text {-wall }}(\mathrm{N} / \mathrm{m})\end{array}$ & $1 \times 10^{8}$ & $1 \times 10^{8}$ & $1 \times 10^{8}$ \\
$\begin{array}{l}\text { Parallel bond radius mul- } \\
\text { tiplier, } r_{p} \text { bond normal }\end{array}$ & 0.5 & $5.68 \times 10^{8}$ & \\
$\begin{array}{l}\text { Parallel bond } \\
\text { stiffness, } k_{n p}(\mathrm{kPa} / \mathrm{m}) \\
\text { Parallel bond shears stiff- } \\
\text { ness, } k_{s p}(\mathrm{kPa} / \mathrm{m})\end{array}$ & $5.68 \times 10^{8}$ & & \\
$\begin{array}{l}\text { Parallel bond normal } \\
\text { strength, } \sigma_{n p}(\mathrm{MPa}) \\
\text { Parallel bond shear } \\
\text { strength, } \sigma_{s p}(\mathrm{MPa})\end{array}$ & 456 & \\
\hline
\end{tabular}

\section{RESULTS AND DISCUSSION}

\subsection{Shear stress-strain and volumetric behaviour of fresh ballast}

An experiment program and DEM simulations for fresh ballast reinforced by geogrid were carried out at three normal stresses of $27 \mathrm{kPa}, 51 \mathrm{kPa}$, and $75 \mathrm{kPa}$. Figure 4 presents comparisons between the DEM simulation and experimental results of the shear stress-strain and the volumetric behaviour of fresh ballast. Overall, the DEM results agreed reasonably well with the experimental results at any given normal stress. The strain softening behavior and volumetric dilation were also captured, such that the higher normal stress, and the greater peak shear stress and smaller dilation were as expected. This strain softening behaviour of fresh ballast followed a similar trend with other rockfills of comparable sizes (e.g., Marsal 1973; Charles and Watts 1980; Indraratna et al. 1998). Figure 4 shows that the DEM results deviate significantly from the experimental data especially around $4-7 \%$ shear strain. This is attributed to the limitations of the DEM model in exactly replicating the true angularity of the actual ballast grains. Although the clustering of spheres of different sizes can represent irregular grain shapes, the large variation of actual particle shapes and their angularity cannot be matched to perfection. 


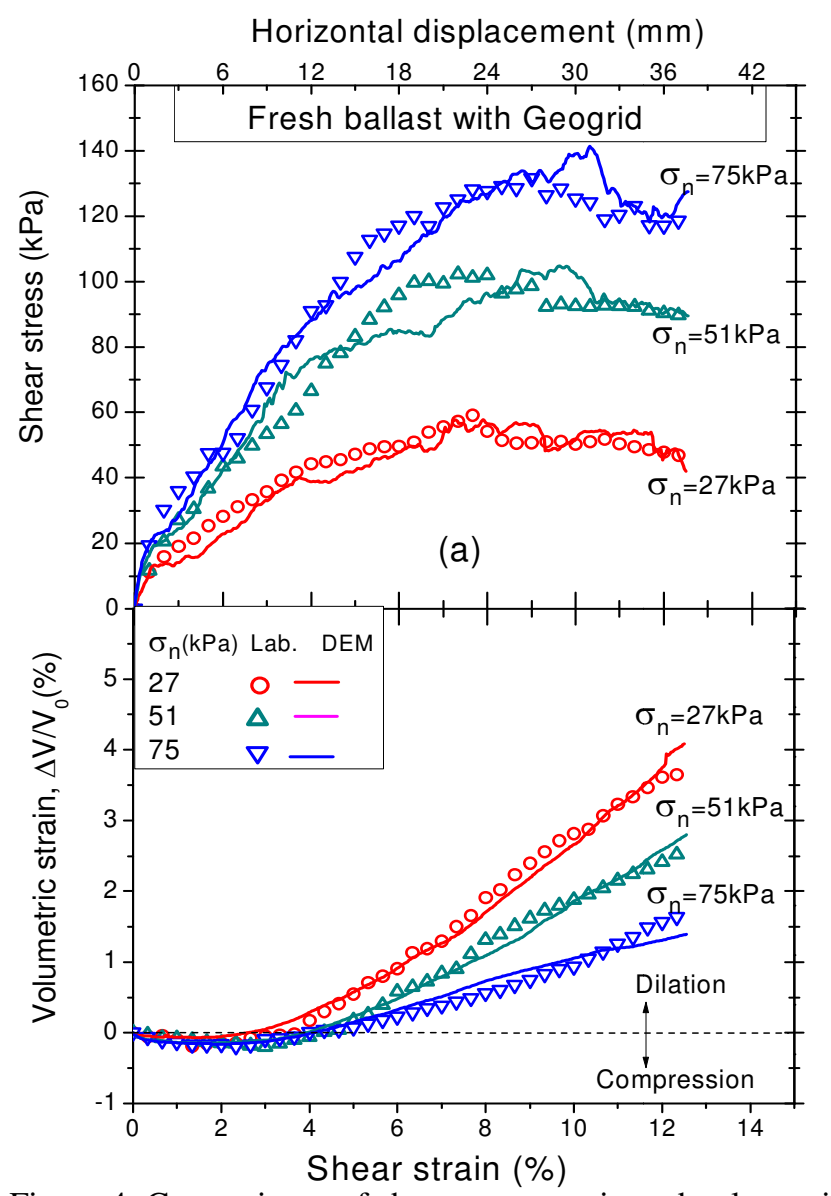

Figure 4. Comparisons of shear stress-strain and volumetric response of fresh ballast between experiment and DEM simulation (modified after Indraratna et al. 2013b)

\subsection{Shear stress-strain and volumetric behavior of $40 \%$ VCI-fouled ballast}

Experiments and DEM simulations of large scale direct shear test for $40 \%$ VCI-fouled ballast reinforced by geogrid were also conducted, and the corresponding stress-strain behaviour is presented in Figure 5. To simulate fouled ballast with $\mathrm{VCI}=40 \%$, a predetermined number of $1.5 \mathrm{~mm}$ spheres (e.g. 145,665 balls) was generated into the voids of fresh ballast. The micromechanical parameters to simulate fouled ballast are given in Table 1. It can be seen here that the shear stress-strain and volumetric behaviour of $40 \%$ VCI-fouled ballast predicted by DEM simulation generally matched well with those obtained in the laboratory. Compared to fresh ballast, the fouled ballast showed a lower peak shear stress and slightly greater dilation, as expected. These observations are primary associated with coal fouling which would decrease the inter-particle friction of ballast particles by coating the surfaces of rough aggregates, and resulting in a reduction in shear strength. Based on these results, it is possible to conclude that the DEM model proposed in this study was able to capture the shear stress-strain and volumetric dilation of fresh and fouled ballast under any given normal stresses.

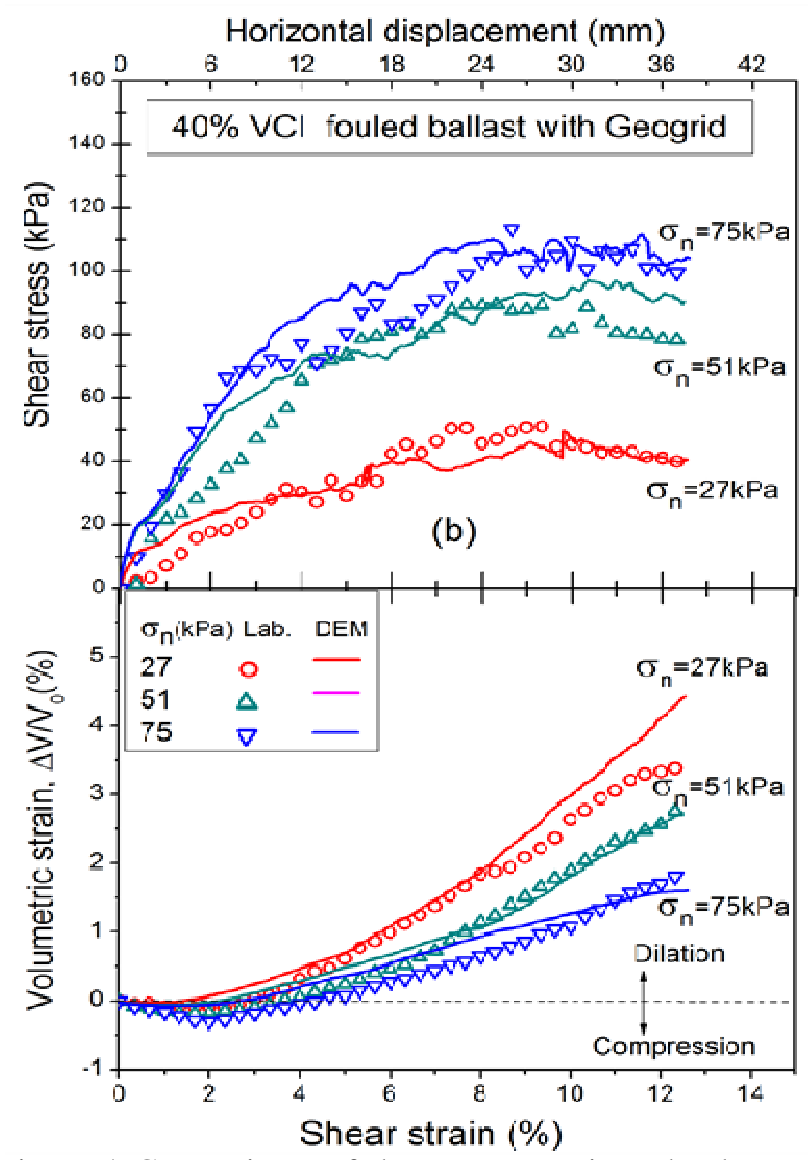

Figure 5. Comparisons of shear stress-strain and volumetric response of $40 \% \mathrm{VCI}-$ fouled ballast between experiment and DEM simulation

\subsection{Contours of strains developed in the geogrid}

Due to the difficulties in installing geogrids and protecting strain gauges from damage caused by the sharp edges of ballast, the strains in the geogrid could not be measured in the laboratory. Taking advantage of DEM simulation, strains that developed across the geogrid in the horizontal shearing direction were captured in this study. Figures 6(a) and 6(b) show the horizontal contours of strain in the geogrid at the end of the shear test for fresh and $40 \%$ VCI fouled ballast, respectively. It can be seen that the strains developed non-uniformly across the geogrid and the magnitude of strain depended on the interlocking that occurred between the geogrid and ballast grains. The geogrid in specimen of fresh ballast exhibited a slightly higher maximum strain than those in the $40 \%$ VCI fouled ballast (i.e. $1.405 \%$ strain for fresh ballast compared to $1.0 \%$ strain in $40 \%$ VCI-fouled ballast). This would be associated with the reduced interlocking effect of the geogrid and ballast aggregates due to coal fines which clog the interface between the ballast and the geogrid. 

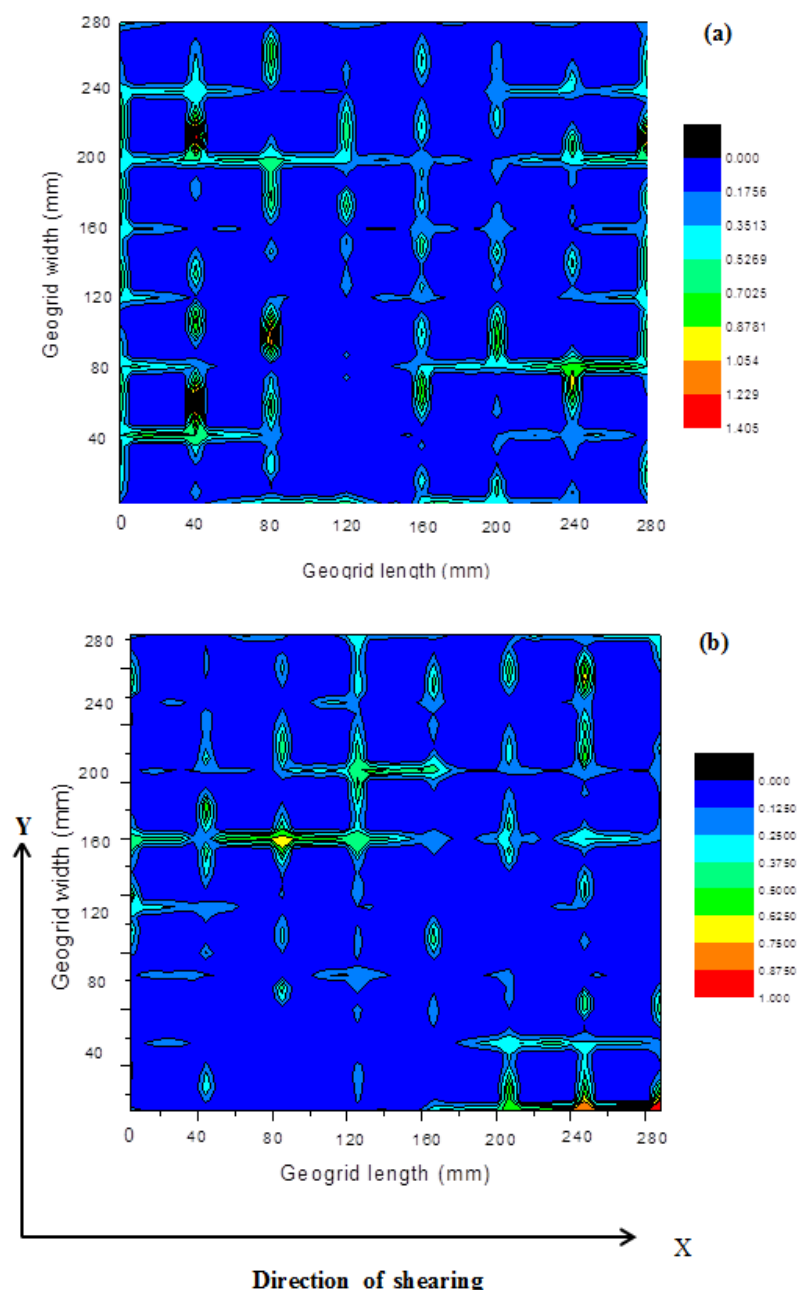

Figure 6. Contour strain developed across the geogrid at the end of test: (a) fresh ballast; (b) 40\%VCI-fouled ballast (modified after Ngo et al. 2014)

\section{CONCLUSION}

A series of experiments and DEM simulations of large scale direct shear tests for fresh and 40\% VCI fouled ballast were carried out to study the volumetric change and corresponding stress-strain behaviour. The tests were conducted at three relatively low normal stresses of $27 \mathrm{kPa}, 51 \mathrm{kPa}$, and $75 \mathrm{kPa}$ to simulate low confining pressure in rail tracks. Irregular particle shapes were modelled by connecting and overlapping a number of spheres together in appropriate sizes and positions. The coal fines were simulated by injecting a specified number of fine spherical particles into the ballast voids. For a given normal stress, the results obtained from the DEM analysis agreed reasonably well with the data measured experimentally, indicating that this DEM model could capture the stress-strain behaviour of fresh and fouled ballast quite adequately. Based on the DEM simulation, the strains developed in the geogrid were also captured. The geogrid in $40 \% \mathrm{VCI}$-fouled ballast exhibited a slightly lower maximum strain than those in fresh ballast, mainly because the fines accumulating in the ballast-geogrid interface reduced the interlock between them.

\section{ADKNOWLEDGEMENT}

The Authors acknowledge the financial support provided by Australian Research Council, Cooperative Research Centre for Rail Innovation, and support from the Centre for Geomechanics and Railway Engineering, University of Wollongong, NSW, Australia. A significant portion of these contents were reproduced with kind permission from Computers and Geotechnics, Geotextiles and Geomembranes and International Journal of Geomechanics, ASCE.

\section{REFERENCES}

Bathurst, R.J. \& Raymond,G.P.1987. Geogrid reinforcement of ballasted track. Transportation Research Record. 1153: 8-14.

Brown, S.F., Kwan, J. \& Thom, N.H. 2007. Identifying the key parameters that influence geogrid reinforcement of railway ballast.Geotextiles and Geomembranes. 25(6): 326-335.

Charles, J.A. \& Watts, K.S. 1980. The influence of confining pressure on the shear strength of compacted rockfill.Geotechnique. 30(4): 353-367.

Cundall, P. A. \& Strack, O. D. L. 1979. A discrete numerical model for granular assemblies.Geotechnique. 29(1): 47-65.

Feldman, F. \& Nissen, D. 2002.Alternative testing method for the measurement of ballast fouling. Conference on Railway Engineering. Wollongong, RTSA.

Ferellec, J.F. \& McDowell, G. R. 2008. A simple method to create complex particle shapes for DEM. Geomechanics and Geoengineering. 3(3): $211-216$.

Ferellec, J.F. \& McDowell, G.R. 2012. Modelling of ballastgeogrid interaction using the discrete-element method. Geosynthetics International. 19(6): 470-479.

Indraratna, B., Ionescu, D. \& Christie, D. 1998. Shear Behaviour of Railway Ballast based on Large Scale Triaxial Testing. Journal of Geotechnical and Geoenvironmental Engineering. 124(5): 439-449.

Indraratna, B., Ngo, N.T \& Rujikiatkamjorn, C. 2013a. "Deformation of Coal Fouled Ballast Stabilized with Geogrid under Cyclic Load". Journal of Geotechnical and Geoenvironmental Engineering, ASCE. 139(8): 1275-1289.

Indraratna, B., Ngo, N.T, Rujikiatkamjorn, C. \& Vinod, J. 2013b. Behaviour of Fresh and Fouled Railway Ballast Subjected to Direct Shear Testing - A Discrete Element Simulation. International Journal of Geomechanics, ASCE. doi:10.1061/(ASCE)GM.19435622.0000264.

Indraratna, B., Ngo, N.T. \& Rujikiatkamjorn, C. 2011. Behavior of geogrid-reinforced ballast under various levels of fouling. Geotextiles and Geomembranes. 29(3): 313-322.

Indraratna, B., Nimbalkar, S. \& Tennakoon, N. 2010. The behaviour of ballasted track foundations: Track Drainage and Geosynthetic Reinforcement. GeoFlorida 2010: Advances in Analysis, Modeling \& Design (GSP 199). Fratta, D., Puppala, A. and Muhunthan, B. (Eds.) 2378-2387. 
Itasca. 2008. Particle flow code in three dimensions (PFC3D). . Itasca Consulting Group, Inc., Minnesota.

Lim, W.L. \& McDowell, G.R. 2005. Discrete element modelling of railway ballast. Granular Matter. 7(1): 19-29.

Lu, M. \& McDowell, G.R. 2007. The importance of modelling ballast particle shape in the discrete elememt method. Granular Matter. 9(1-2): 69-80.

Marsal, R.J. 1973. Mechanical properties of Rockfill. In : Embankment Dam Engineering Wiley, New York, pp: 109-200.

McDowell, G. R., Harireche, O., Konietzky, H., Brown, S. F. \& Thom, N.H. 2006. Discrete element modelling of geogrid-reinforced aggregates. Proceedings of the ICE - Geotechnical Engineering 159(1): 35-48.

Ngo, N.T., Indraratna, B. \& Rujikiatkamjorn, C. 2014. DEM simulation of the behaviour of geogrid stabilised ballast fouled with coal. Computers and Geotechnics. 55: 224-231.

Raymond, G.P. 2002. Reinforced ballast behaviour subjected to repeated load. Geotextiles and Geomembranes. 20(1): 39-61.

Selig, E.T. \& Waters, J.M. 1994. Track geotechnology and substructure management, Thomas Telford, London.

Shukla, S.K. \& Yin, J.H. 2006. Fundamentals of Geosynthetic Engineering, Taylor \& Francis Group, London, UK.

Thakur, P. K., Vinod, J. S. \& Indraratna, B. 2010. Effect of particle breakage on cyclic densification of ballast: A DEM approach.Materials Science and Engineering. 10: $1-7$.

Tutumluer, E., Huang, H. \& Bian, X. 2011. Geogrid-aggregate interlock mechanism investigated through aggregate imaging based discrete element modeling approach. International Journal of geomechanics, ASCE. 12(4): 391-398. 